\title{
Bowman's layer transplantation: evidence to date
}

This article was published in the following Dove Press journal:

Clinical Ophthalmology

\author{
Bhavana Sharma' \\ Aditi Dubey ${ }^{2}$ \\ Gaurav Prakash ${ }^{3}$ \\ Rasik B Vajpayee ${ }^{4-6}$ \\ 'Department of Ophthalmology, All \\ India Institute of Medical Sciences, \\ Bhopal, India; ${ }^{2}$ Department of \\ Ophthalmology, Gandhi Medical \\ College, Bhopal, India; ${ }^{3}$ Cornea and \\ Refractive Surgery Services, NMC \\ Eye Care, New Medical Center \\ Specialty Hospital, Abu Dhabi, United \\ Arab Emirates; ${ }^{4}$ Vision Eye Institute, \\ Melbourne, VIC, Australia; ${ }^{5}$ Royal \\ Victorian Eye and Ear Hospital, \\ Melbourne, VIC, Australia; ${ }^{6}$ North \\ West Academic Centre, University of \\ Melbourne, Melbourne, VIC, Australia
}

Correspondence: Rasik B Vajpayee Royal Victorian Eye and Ear Hospital, 32 Gisborne Street, East Melbourne, VIC 3002, Australia

Email rasikv@unimelb.edu.au

\begin{abstract}
Surgical management of keratoconus $(\mathrm{KC})$ has undergone a paradigm shift in the last two decades and component corneal transplantation technique of deep anterior lamellar keratoplasty has established itself as a modality of choice for management of advanced cases of KC. Every now and then, new minimalist modalities are being innovated for the management of $\mathrm{KC}$. On the same lines, a new technique, Bowman's layer transplantation, for surgical management of moderate to advanced $\mathrm{KC}$ has been reported in recent years. The procedure has shown to be beneficial in reducing ectasia in advanced $\mathrm{KC}$ with minimal intraoperative and postoperative complications. In this review, we intend to describe available information and literature with reference to this new surgical technique - Bowman's layer transplantation.
\end{abstract}

Keywords: keratoconus, Bowman's Layer, keratoplasty, post PRK haze, component keratoplasty

\section{Introduction}

Keratoconus $(\mathrm{KC})$ is an ectatic disorder of the eye which results in progressive thinning of the cornea leading to visual and structural abnormalities. One of the essential pathognomic features in advanced $\mathrm{KC}$ is fragmentation of the Bowman's layer (BL)., Recently it has been hypothesized that a partial restoration of the corneal anatomy might be obtained through a mid-stromal implant of an isolated BL graft to flatten the corneal curvature. ${ }^{3}$ The procedure has shown to be beneficial in reducing ectasia in advanced $\mathrm{KC}$ with minimal intraoperative and postoperative complications.

The donor Bowman's layer transplantation (BLT) into the mid-stroma functions to pull, strengthen and make the anterior corneal surface flatter. ${ }^{4}$ Good outcomes of BLT in the management of persistent subepithelial haze after excimer laser surface procedure have also been reported. ${ }^{5}$ These two uses of BLT have put forth its importance as a new modality of management of $\mathrm{KC}$ and post-laser surface complications.

In this review, we describe available information and literature concerning this new surgical technique - BLT.

\section{Anatomical considerations}

The human cornea is made of the five distinct layers: epithelium and BL anteriorly; and endotheliumand Descemet's membrane (DM), posteriorly, sandwiching the stroma. The anterior stroma is more compact than the posterior due to the different composition of proteoglycans..$^{6-8}$

The BL is an acellular layer that acts as an interface between the corneal epithelium and stroma. It is $\sim 12 \mu \mathrm{m}$ thick and is a random arrangement of collagen fibrils (predominantly types I and III) and proteoglycans. ${ }^{9,10}$ The diameter of these fibrils is $20-30 \mathrm{~nm} .{ }^{9}$ The BL has an average radius of $7.34 \mathrm{~mm}^{11}$ and it gets thinner with age. ${ }^{12}$ 
The precise functional role of $\mathrm{BL}$ is unclear, and it has been suggested that it may be superfluous to human corneal functions. The reason for this hypothesis is the absence of adverse complications in many eyes that lose BL after having undergone excimer laser photorefractive keratectomy (PRK). ${ }^{13}$

Over last few years, there have been successful attempts to isolate BL., This is in lines of the current trend towards component corneal keratoplasty mainly deep anterior lamellar keratoplasty (DALK) and Descemet's stripping automated endothelial keratoplasty after splitting of donor corneal tissues in various components. These procedures have resulted in an additional benefit of optimum utilization of donor corneas. ${ }^{14}$

\section{Indications for BLT}

Isolated donor BLT has been utilized mainly to treat two corneal conditions: as an inlay graft into the mid stroma of the cornea for treatment of $\mathrm{KC}$, and as an onlay graft for treatment of persistent subepithelial haze, seen in some cases after excimer laser surface ablation. ${ }^{3,5}$

\section{$\mathrm{KC}$}

$\mathrm{KC}$ is a bilateral asymmetric ectatic corneal dystrophy and has been classically defined as a progressive, non-inflammatory condition, which produces a thinning and steepening of the cornea. ${ }^{15-17}$ Visual loss occurs primarily from irregular astigmatism, myopia and secondarily from corneal scarring. Various modalities for surgical treatment for mild to moderate $\mathrm{KC}$ include corneal crosslinking (CXL), and Intracorneal rings and for advanced cases, it has been either penetrating keratoplasty (PK) or DALK. ${ }^{17}$ In advanced cases, none of the other measures can lead to satisfactory visual recovery. In such cases, the choice of the surgeon gets limited to corneal transplantation. Transplantation procedures for $\mathrm{KC}$ mainly comprise PK and DALK..$^{18,19}$ DALK has the unique benefit of host endothelium retention, which contrasts it from PK where the structural and immunologic integrity of the eye is breached. However, both these surgical modalities (PK and DALK) can weaken the corneal structure and are associated with many intraoperative and postoperative complications.

Hence, there have been ongoing efforts to find a surgical alternative that is simple and devoid of most of the complications associated with PK and DALK. BLT is the latest surgical modality being tried for surgical treatment of $\mathrm{KC}$. However, it remains to be seen whether it is equal to, or better than current modalities of $\mathrm{KC}$ management.
If proven successful in the future, it would be another addition in the armamentarium of corneal transplantation surgeons that may be safer than PK or DALK. A BLT in a keratoconic eye aims to reinforce thin and structurally fragile cornea making it stiffer and flatter. ${ }^{3}$ The primary claimed advantage of the procedure is that it may arrest the progression of $\mathrm{KC}$, thereby preserving, and in some cases restoring, contact lens tolerance. As a result, patients may achieve stability of vision and may postpone or avoid surgical alternatives of DALK/PK. The ideal candidates for this technique are those with progressive advanced $\mathrm{KC}$, with good contact lens corrected vision, who are not eligible for collagen crosslinking and have increasingly worsening contact lens tolerance. Patients with associated central scarring are potentially not suitable candidates for the procedure. ${ }^{3,4}$

\section{Post excimer laser corneal haze}

Corneal haze occurring after excimer laser surface ablation has been known to cause loss of best-corrected vision and reduced quality of vision. Corneal stromal haze seen after excimer laser surface ablation has been shown to be associated with increased ablation depth and aggressive healing response. ${ }^{20-23}$ Besides the ablation depth, the severity of corneal haze is correlated with excessive ocular ultraviolet radiation, post-ablation epithelial defect duration, male gender, and with certain populations with brown iris. ${ }^{24}$ Occurrence of corneal haze after PRK been blamed on cytokines and growth factors released in anterior stroma due the destruction of basement membrane leading to activation of keratocytes which synthesize large diameter collagen fibrils. ${ }^{24}$ Corneal transparency is reduced due to the abnormally deposited extracellular matrix. ${ }^{24,25}$ Currently, the options to mitigate the risk of occurrence of haze are either use of intraoperative Mitomycin drops or prolonged postoperative steroids. ${ }^{26,27}$ Both these therapies may have associated side effects and may not be successful in all cases.

BLT is the new technique that claims to manage corneal scarring and haze seen after PRK. The technique involves superficial dissection of scar followed by isolated BLT. Promising results were seen over a period of 6 months, with no recurrent scarring and improvement in visual acuity with a scleral-supported hard contact lens. ${ }^{5}$ As mentioned earlier, the postulated cause of subepithelial haze in such cases is a loss of barrier between epithelium and stroma which in turn leads to abnormal wound-healing response. A donor Bowman graft may rebuild the corneal structure by restoring 
a normal anatomical barrier between the epithelium and underlying stroma.

\section{Surgical technique of BLT Preparation of BL lenticule}

The donor graft is harvested manually by peeling the BL from the anterior stroma of the donor cornea. It can harvested from either whole donor globes mounted on a holder (technique I), or corneoscleral rims mounted on an artificial chamber (technique II). ${ }^{28}$

Parker et al advocated utilization of donor whole globes which may not be suitable for keratoplasty either PK or lamellar keratoplasty. ${ }^{29}$

Preparation from corneoscleral rims may offer the advantage that, from one donor cornea, the posterior layers can be used for Descemet's membrane endothelial keratoplasty graft preparation and the anterior part for BL graft preparation.

Corneoscleral rims that have been used to harvest DMEK grafts can be successfully used later to harvest BL graft, allowing one donor tissue to be used for two recipients. Rates of successful harvesting of BL were comparable between whole globes and corneoscleral rims (69.4\% [25/36] and $72.2 \%$ [26/36] for techniques I and II, respectively). ${ }^{28}$ Tearing of the BL during preparation, and an unusually thick graft were the main reasons for discarding the donor BL grafts. Imprecise surgical manipulations may yield either a thick BL graft or may lead to penetration/buttonholing of BL. A thick BL tissue does not roll and may lie flat. Presence of extra stromal tissue attached to BL it can compromise visual quality after transplantation due to haze at the graft-recipient interface. An ideal BL graft has only a thin layer of stromal tissue on its under-surface.

Recently femtosecond laser is being investigated for harvesting the donor BL. Initial, feasibility analysis has shown the creation of a thick but relatively smooth posterior cut edge in the femtosecond laser group, versus a virtually isolated $\mathrm{BL}$ with irregular rests of dispersed stroma in the manually dissected group. ${ }^{30}$

\section{BLT procedure}

The principle of the surgical technique is to implant BL donor graft in the midstroma of recipient keratoconic cornea. ${ }^{3}$ The procedure involves creation of a mid-stromal pocket in the recipient cornea over complete circumference from limbus to limbus with air-endothelial reflex guiding the precise dissection at a depth of about $50 \% .{ }^{4}$ Subsequently, BL graft is stained with trypan blue stained and is transplanted in the stromal pocket with the help of a glide.

\section{Outcomes}

BLT is a relatively new surgical modality with limited literature available. The short- and mid-term results are available and show its efficacy in cases of advanced KC. van Dijk et al were first to report the success of BL transplantation in the management of $\mathrm{KC} .{ }^{3,31}$ In their two reports of 10 and 22 cases, respectively, a decrease in the corneal curvature was noted after the procedure. The contact lens-corrected visual acuity was stable, with improved lens fits. There was a trend towards improvement in spectacle-corrected visual acuity, which achieved statistical significance in the larger study of 22 cases. Their results demonstrate that isolated BLT can reduce and stabilize corneal ectasia in eyes with progressive, advanced $\mathrm{KC}$ and they concluded that BL transplantation could be used to postpone a penetrating or deep anterior lamellar keratoplasty. Luceri et al evaluated corneal densitometry and higher-order aberrations (HOAs) after BLT and found that HOAs like spherical aberration, decreased for both anterior and posterior corneal surfaces, whereas corneal backscattering increased. ${ }^{32}$ However, these changes did not correlate with corrected distance visual acuity.

The results of BLT in in post-PRK haze have been claimed to be encouraging in early follow-up (6 months), with the case achieving a contact lens-corrected visual acuity of 20/18 within 2 months. ${ }^{5}$ The results of BLT are summarized in Table 1.

A major advantage of BLT is that it is a suture less procedure. In addition, as the graft is acellular, the risk of allograft reaction may be significantly reduced. Substantially lower postoperative steroid burden reduces the occurrence of steroid-related complications of cataract and glaucoma. The procedure entails a lower risk of complications seen with intraocular procedures such as post-surgical endophthalmitis and choroidal hemorrhage since it does not involve any intraocular manipulations. BLT appears to be minimally invasive procedure where surgical manipulations are confined to a pocket within the recipient cornea. In addition, the transplanted tissue may be removed later if necessary. However, the technique of BLT is a relatively tedious and complex surgical procedure requiring expertise and appears to carry a steep learning curve. In future, use of femtosecond laser to harvest the graft and to dissect the host cornea may make this technique easier to practice and achieve optimal visual outcomes. ${ }^{30}$

Management of KC can not be adequately achieved by a single treatment plan, owing to the fact that treatment protocols differ with staging of disease and progressive nature of disease. Spectacle correction, contact lenses or CXL may 
Table I Outcomes of Bowman's layer transplantation

\begin{tabular}{|c|c|c|c|c|c|c|}
\hline S no & Author & Study type & Indication & $\begin{array}{l}\text { Sample } \\
\text { size }\end{array}$ & Outcome & Complications \\
\hline I. & $\begin{array}{l}\text { van Dijk K et al } \\
(20 \mid 4)^{3}\end{array}$ & Prospective & $\begin{array}{l}\text { Progressive, advanced } \\
\mathrm{KC} \text { and contact lens } \\
\text { intolerance }\end{array}$ & 10 & $\begin{array}{l}\text { Decreased mean maximal corneal } \\
\text { power } 74.5-68.3 \mathrm{D}\end{array}$ & None \\
\hline 2. & $\begin{array}{l}\text { van Dijk K et al } \\
(2015)^{31}\end{array}$ & Prospective & $\begin{array}{l}\text { Advanced KC } \\
(K \max \geq 70.00 \mathrm{D})\end{array}$ & 22 & $\begin{array}{l}\text { Decreased keratometry } \\
77.2 \pm 6.2 \mathrm{D} \text { to } 69.2 \pm 3.7 \mathrm{D}\end{array}$ & $\begin{array}{l}\text { Intraoperative perforation of } \\
\text { Descemet's membrane }\end{array}$ \\
\hline 3. & $\begin{array}{l}\text { Luceri et al } \\
(2016)^{32}\end{array}$ & Retrospective & Advanced KC & 15 & Reduction in corneal $\mathrm{HOA}$ & Increased corneal backscattering \\
\hline 4. & $\begin{array}{l}\text { Parker et al } \\
(2017)^{29}\end{array}$ & Case report & Progressive KC & I & $\begin{array}{l}\text { Kmean decreased by } 1.40 \mathrm{D} \text { Kmax } \\
\text { By nearly } 5.00 \mathrm{D}\end{array}$ & None \\
\hline 5. & Lie et al $(2010)^{5}$ & Case report & $\begin{array}{l}\text { Persistent dense } \\
\text { subepithelial haze after } \\
\text { PRK }\end{array}$ & I & $\begin{array}{l}\text { CDVA improved from } 20 / 40 \text { before } \\
\text { surgery to } 20 / 18 \text { ( } 2 \text { months post-op, } \\
\text { scleral-supported contact lens) }\end{array}$ & None \\
\hline
\end{tabular}

Abbreviations: CDVA, corrected distance visual acuity; HOA, higher order aberrations; PRK, photorefractive keratectomy; post-op, post-operative; Kmax, Keratometry maximum; $\mathrm{K}$ mean, Keratometry mean.

improve visual functions in mild to moderate cases, moderate to severe cases may require corneal transplantation. In addition combination procedures such as CXL plus other procedures (eg, CXL plus Intacs; CXL plus phakic intraocular lens; CXL plus PRK) have been utilized to achieve long term stability and improvement in visual functions.

The procedure of BLT, though in its infancy may become a good alternative, in terms of structural outcome, to some of the existing surgical treatment modalities for KC. Though it is associated with only a modest visual improvement, reduction and stabilization of corneal ectasia achieved can prevent further progression of $\mathrm{KC}$.

\section{Conclusion}

Isolated BLT is a new and evolving technique for the management of KC. It has also been used for the treatment of persistent corneal haze seen after excimer laser surface ablation. The technique is in its early days, and presently there is not enough evidence for this technique to be practiced as a routine surgical modality.

\section{Disclosure}

The authors report no conflicts of interest in this work.

\section{References}

1. Mas Tur V, MacGregor C, Jayaswal R, O’Brart D, Maycock N. A review of keratoconus: diagnosis, pathophysiology, and genetics. Surv Ophthalmol. 2017;62(6):770-783.

2. Ambekar R, Toussaint KC Jr, Wagoner Johnson A. The effect of keratoconus on the structural, mechanical, and optical properties of the cornea. J Mech Behav Biomed Mater. 2011;4(3):223-236.

3. van Dijk K, Parker J, Tong CM, et al. Midstromal isolated Bowman layer graft for reduction of advanced keratoconus: a technique to postpone penetrating or deep anterior lamellar keratoplasty. JAMA Ophthalmol. 2014;132(4):495-501.
4. Parker JS, van Dijk K, Melles GR. Treatment options for advanced keratoconus: a review. Surv Ophthalmol. 2015;60(5):459-80:459-480.

5. Lie J, Droutsas K, Ham L, et al. Isolated Bowman layer transplantation to manage persistent subepithelial haze after excimer laser surface ablation. J Cataract Refract Surg. 2010;36(6):1036-1041.

6. Muller LJ, Pels E, Vrensen GF. The specific architecture of the anterior stroma accounts for maintenance of corneal curvature. Br JOphthalmol. 2001;85(4):437-443.

7. Bettelheim FA, Plessy B. The hydration of proteoglycans of bovine cornea. Biochem Biophys Acta. 1975;381(1):203-214.

8. Bron AJ. The architecture of the corneal stroma. Br JOphthalmol. 2001; 85(4):379-381.

9. Nishida T, Saika S, Morishige N. Cornea and Sclera: Anatomy and Physiology. In: Mannis MJ, Holland EJ, eds. Cornea. New York: Elsevier Inc.; 2017:1-22.

10. Wilson SE, Hong JW. Bowman's layer structure and function: critical or dispensable to corneal function? A hypothesis. Cornea. 2000;19(4): 417-420.

11. Patel S, Reinstein DZ, Silverman RH, Coleman DJ. The shape of Bowman's layer in the human cornea. $J$ Refract Surg. 1998;14(6):636-640.

12. Germundsson J, Karanis G, Fagerholm P, et al. Age-related thinning of Bowman's layer in the human cornea in vivo. Invest Ophthalmol Vis Sci. 2013;54(9):6143-6149.

13. Lagali N, Germundsson J, Fagerholm P. The role of Bowman's layer in corneal regeneration after phototherapeutic keratectomy: a prospective study using in vivo confocal microscopy. Invest Ophthalmol Vis Sci. 2009;50(9):4192-4198.

14. Vajpayee RB, Sharma N, Jhanji V, et al. One donor cornea for 3 recipients: a new concept for corneal transplantation surgery. Arch Ophthalmol. 2007;125:552-554.

15. Kennedy RH, Bourne WM, Dyer JA. A 48-year clinical and epidemiologic study of keratoconus. Am J Ophthalmol. 1986;101:267-273.

16. Rabinowitz YS. Keratoconus. Surv Ophthalmol. 1998;42:297-319.

17. Jhanji V, Sharma N, Vajpayee RB. Management of keratoconus: current scenario. Br J Ophthalmol. 2011;95:1044-1050.

18. Watson SL, Ramsay A, Dart JK, et al. Comparison of deep lamellar keratoplasty and penetrating keratoplasty in patients with keratoconus. Ophthalmology. 2004;111(9):1676-1682.

19. Shimazaki J, Shimmura S, Ishioka M, et al. Randomized clinical trial of deep lamellar keratoplasty vs penetrating keratoplasty. Am J Ophthalmol. 2002;134:159-165.

20. Gartry DS, Kerr Muir MG, Marshall J. Excimer laser photorefractive keratectomy: 18 month follow-up. Ophthalmology. 1992;99: 1209-1219. 
21. Liu JC, McDonald MB, Varnell R, et al. Myopic excimer laser photorefractive keratectomy: an analysis of clinical correlations. Refract Corneal Surg. 1990;6:321-328.

22. Sher NA, Barak M, Daya S, et al. Excimer laser photorefractive keratectomy in high myopia. Arch Ophthalmol. 1992;110:935-943.

23. Kaiserman I, Sadi N, Mimouni M, et al. Corneal breakthrough haze after photorefractive keratectomy with mitomycin $\mathrm{C}$ : incidence and risk factors. Cornea. 2017;36(8):961-966.

24. Tomás-Juan J, Murueta-GoyenaLarrañaga A, Hanneken L. Corneal regeneration after photorefractive keratectomy: a review. J Optom. 2015;8(3):149-169.

25. Torricelli AA, Singh V, Agrawal V, et al. Transmission electron microscopy analysis of epithelial basement membrane repair in rabbit corneas with haze. Invest Ophthalmol Vis Sci. 2013;54:4026-4033.

26. Hofmeister EM, Bishop FM, Kaupp SE, et al. Randomized doseresponse analysis of mitomycin-C to prevent haze after photorefractive keratectomy for high myopia. J Cataract Refract Surg. 2013;39(9): $1358-1365$.
27. Majmudar PA, Schallhorn SC, Cason JB, et al. Mitomycin-C in corneal surface excimer laser ablation techniques: a report by the American Academy of Ophthalmology. Ophthalmology. 2015;122(6):1085-1095.

28. Groeneveld-van Beek EA, Parker J, Lie JT, et al. Donor tissue preparation for Bowman layer transplantation. Cornea. 2016;35(12):1499-1502.

29. Parker J, van Dijk K, Cooper E, Melles, GRJ. Bowman layer transplantation for advanced keratoconus. Cataract \& Refractive Surgery Today Europe. 2017:30-33.

30. Parker JS, Huls F, Cooper E, et al. Technical feasibility of isolated Bowman layer graft preparation by femtosecond laser: a pilot study. Eur J Ophthalmol. 2017. [Epub ahead of print].

31. van Dijk K, Liarakos VS, Parker J, et al. Bowman layer transplantation to reduce and stabilize progressive, advanced keratoconus Ophthalmology. 2015;122(5):909-917.

32. Luceri S, Parker J, Dapena I, et al. Corneal densitometry and higher order aberrations after Bowman layer transplantation: 1-year results. Cornea. 2016;35(7):959-966.
Clinical Ophthalmology

\section{Publish your work in this journal}

Clinical Ophthalmology is an international, peer-reviewed journal covering all subspecialties within ophthalmology. Key topics include: Optometry; Visual science; Pharmacology and drug therapy in eye diseases; Basic Sciences; Primary and Secondary eye care; Patient Safety and Quality of Care Improvements. This journal is indexed on

Submit your manuscript here: http://www.dovepress.com/clinical-ophthalmology-journal

\section{Dovepress}

PubMed Central and CAS, and is the official journal of The Society of Clinical Ophthalmology (SCO). The manuscript management system is completely online and includes a very quick and fair peer-review system, which is all easy to use. Visit http://www.dovepress.com/ testimonials.php to read real quotes from published authors. 